\title{
Intelligent Treasury Management (ITM). Investment Decision Making Under the Models of Miller and Orr and Markowitz
}

\author{
Romel Ramón González Díaz and Luis Armando Becerra Peréz \\ University of Sinú \\ Autonomous University of Sinaloa
}

\begin{abstract}
Investment decisions in business finance are decisive to improve the cyclical fluctuation of any form of business, minimize opportunity costs and maximize idle fund returns. Empirical evidence has shown that the agricultural sector has only two financial periods in the year: surplus and deficit. If in some of these periods good decisions are not taken, serious financial problems could be generated. Therefore, this study presents an analysis of the treasury management of the microenterprises of the agricultural sector of the Colombian Caribbean region, based on cash flow management models proposed by Miller and Orr, who consider the volatility of cash balances and project trends in the upper and lower limits of the optimal cash balances. This indicates to the financial management the moment of acquiring a type of financial instrument. In the cases of acquisition of financial assets, the optimal investment portfolio is determined in relation to the profitability and risk of the 3 shares with the highest participation in the COLCAP index: ECOPETROL, PFBCOLOM and GRUPOSURA, based on the Markowitz model.
\end{abstract}

Keywords: Miller and Orr model; Markowitz model; Investment decisions; Cash flow; Investment portfolio. 